\title{
A CONTEXTUALIZAÇÃO TEMÁTICA DA MORTE NAS BIOGRAFIAS DE PLUTARCO: ALGUNS EXEMPLOS ${ }^{1}$
}

\author{
Joaquim Pinheiro* \\ Recebido em: 09/05/2018 \\ Aprovado em: 01/09/2018
}

RESUMO: No género biográfico, a narrativa termina, em geral, com a descrição das circunstâncias da morte do biografado. Como Plutarco, nas Vidas, nem sempre segue este mesmo padrão, propomo-nos identificar as principais formas de conclusão das biografias. Depois, partindo de uma selecção de bioi suficientemente representativos das diversas tipologias, analisaremos as variações e o sentido que a morte do herói confere à sua caracterização ético-moral.

PALAVRAS-CHAVE: Plutarco; Vidas Paralelas; morte; biografia.

\section{THE DESCRIPTION OF DEATH IN PLUTARCH'S LIVES: SOME EXAMPLES}

* Universidade da Madeira, Faculdade de Artes e Humanidades. Investigador do Centro de Estudos Clássicos e Humanísticos, Universidade de Coimbra. pinus@uma.pt

\begin{abstract}
In the biographical literary genre, the narrative usually ends with the description of the circumstances of the hero's death. As Plutarch, in his Lives, does not always follows this pattern, in this study we will identify the main forms of the conclusion of the biographies. Then, starting from a selection of bioi sufficiently representative of the different typologies identified, we will analyse the variations and the sense that the death of the hero confers to its ethical and moral characterization.
\end{abstract}

KEYWORDS: Plutarch; Lives; death; biography.

\footnotetext{
${ }^{1}$ Este estudo foi desenvolvido no âmbito do Projecto "Roma nosso lar: tradição (auto)biográfica e consolidação da(s) identidade(s)" [PTDC/LLTOUT/28431/2017], financiado pela Fundação para a Ciência e a Tecnologia (Portugal). Acrescente-se que, por opção do autor, este artigo não adopta o Acordo Ortográfico da Língua Portuguesa (1990).
} 
A sequência normal da narrativa biográfica conduz-nos do nascimento até às $A$ circunstâncias da morte. Nas Vidas de Plutarco, é isso que sucede na maioria das $\mathcal{L}$ vezes, mas nem sempre da mesma forma, pois o biógrafo não segue uma metodologia uniforme. $\mathrm{O}$ facto de as Vidas estarem agrupadas em pares, um grego e um romano em paralelo, geralmente por esta ordem ou pela ordem inversa em dois casos (Coriolano-Alcibiades e Sertório-Êmenes), a que se junta uma terceira parte chamada sýnkrisis, salvo alguma excepções, obriga a uma leitura de conjunto, mesmo quando nos propomos identificar as formas de descrição da morte do herói, na conclusão das biografias.

De facto, a escrita biográfica de Plutarco repete alguns aspectos formais. Em geral, as biografias são introduzidas por uma espécie de prólogo, em que Plutarco tece breves considerações sobre a escolha dos biografados e os motivos do paralelismo, estabelecendo os primeiros laços da relação entre narrador e narratário, e esclarece algumas linhas programáticas. ${ }^{4}$ Após esta parte, o autor de Queroneia desenvolve um conjunto de elementos que considera dignos de serem preservados pela memória ( $\left.\alpha \xi_{1} \alpha \mu v \eta \dot{\mu} \mu \varsigma^{5}\right)$. Esse conjunto abarca, normalmente, três partes. ${ }^{6}$ A primeira parte contempla os primeiros anos, desde o nascimento até ao início da actividade pública:
a) a origem e o estatuto social da personagem;
b) a caracterização física, distribuída pela narrativa, aproveitada, algumas vezes, para realçar uma qualidade moral; ${ }^{7}$
c) as qualidades espirituais, importantes no conteúdo didáctico-moral;

\footnotetext{
${ }^{2}$ Eagleton (1993, p. 12); embora se compreenda o sentido desta frase, nem sempre a narrativa biográfica é assim tão linear. Porfírio, por exemplo, inicia a biografia de Plotino com a referência à morte.

${ }^{3}$ Gribble (1999, p. 281).

${ }^{4}$ Refira-se que nos pares Sol. -Pub., Them-Cam, Arist-Cat. Ma, Cor-Alc, Phil-Flam, Pyrrh-Marc, Lyc-Num, Lys-Sull e Ages-Pomp falta o prólogo; para uma análise sistemática desta estrutura e do seu papel na tradição biográfica vide Stadter (1988, p. 275-95), Rosenmeyer (1992, p. 205-30), Duff (2002r, p. 53), Pelling (2002a, p. 267-82).

${ }^{5}$ Cf. Comp. Dem Cic 1.1.

${ }^{6}$ Cf. Pérez Jiménez (2000r, p. 100-5), que serviu de modelo para a nossa estrutura. Para as $1^{\text {a }}$ e $2^{\text {a }}$ Partes, vide Polman (1974, p. 169-77); sobre estes aspectos formais das biografias, vide Pinheiro (2008, 2013, p. 25-84).

${ }^{7}$ E. g. Caes. 17.2; Per. 5.1.; Ag./Cleom. 2.4; Ant. 4.1; Arat. 3.2; Cat. Mi. 1.3; Demet. 2.2; Mar., 2.1; Phoc. 5; Pyrrh. 3.3-6; Sull.2.1-2 e Gracch. 2.2.; em alguns casos a descrição física é exigida pela própria narrativa, como em Cic. 3.7, Dem. 4.4, Per. 7, 1-2 e Thes. 6.2.
} 
d) a formação da personagem, acreditando-se que a paideía tem um papel vital no comportamento do indivíduo ${ }^{8}$ daqui resulta, por vezes, a exploração da emulação por parte de Plutarco, que tem como finalidade revelar o carácter e a consequente orientação na vida pública;

e) a iniciação na vida pública, fase que marca a passagem da juventude para a idade adulta.

A segunda parte apresenta os principais feitos da idade adulta, ao nível da acção militar e política, em que se estabelece uma relação entre as práxeis e o êthos:

a) os primeiros feitos que levam ao reconhecimento público;

b) a akmé do herói, lembrando o biógrafo as razões;

c) os últimos feitos ou acções do herói.

$\mathrm{Na}$ terceira parte, por fim, Plutarco recolhe informações várias sobre a morte do herói ${ }^{9}$ e a sua memória (o cadáver, a descendência e as homenagens dos cidadãos), descrição feita com maior ou menor dramatismo, consoante se trate de um suicídio, ${ }^{10}$ de um assassinato ${ }^{11}$ ou inclua a reprodução dos ultima verba do herói. ${ }^{12}$

Esta estrutura, do génos até à morte, ajudaria certamente o autor a organizar o material que tinha disponível, servindo como uma forma aproximada de índice de matérias.

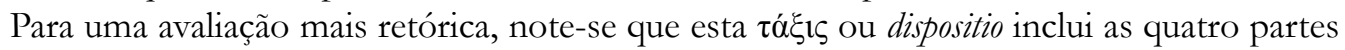

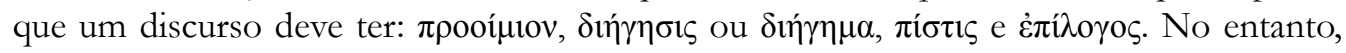
Plutarco nem sempre segue com rigor esta ordem na sua narrativa biográfica: nos bioi de César e Nícias não temos qualquer referência ao génos, à familia ou à formação, nas vidas de Publícola, Camilo e Fábio Máximo, por sua vez, a narração começa na idade adulta. Além disso, o peso que cada uma das partes tem na economia narrativa é também diferente: por exemplo, a descrição do assassinato de César é mais extensa do que a narração do fim de Alexandre. ${ }^{13}$ Pelling (2002b, p. 366) afirma que Plutarco dedica, em média, à morte e ao momento post mortem quarenta e cinco linhas, no formato da edição teubneriana, ou seja,

\footnotetext{
${ }^{8}$ Cf. Alex. 7-8 e Cat. Ma. 2,4; Cat. Mi. 4.2; Brut. 1.3; Dion 4. 6; noutros casos, Plutarco realça os efeitos da ausência da paideía: por exemplo, Alc. 2.1, Cim. 4.5, Cor. 1.3, Mar. 2.3, Them. 2.7.

${ }^{9}$ Há casos em que Plutarco não termina com a morte do protagonista da biografia, mas com um ou mais capítulos dedicados aos descendentes ou ao destino dos seus inimigos; Dem. 31, Pel. 35, Demetr. 53 e Ant. 78-81, são alguns exemplos.

${ }^{10}$ E.g. Dem. 29, Ant. 77, Cleom. 31 e Brut. 40.5-12; para uma análise da práxis do suicídio, vide Lyc. 29: tendo por fonte, muito provavelmente, o historiador Éforo, Plutarco narra o episódio que levou Licurgo a suicidar-se, depois de ter obtido a confirmação por parte do oráculo de Delfos de que as suas leis garantiriam eudaimonía e aretê para a pólis. Plutarco entende que, tendo em conta a sua idade, ele já tinha atingido a eudaimonía suficiente.

${ }^{11}$ E.g. Pomp. 78-79 e Caes. 66.

${ }^{12}$ E.g. Eum. 17.5-18.2.

${ }^{13}$ Cf. Caes. 63-68. e Alex. 75, respectivamente.
} 
quatro por cento do total, percentagem média que não deixa de ser significativa, sobretudo se tivermos em conta que em algumas biografias, como as de António, Rómulo, Pelópidas ou Licurgo esse valor é claramente ultrapassado, enquanto em outras, como na vida de Camilo, sucede o contrário.

A falta de uma metodologia coerente e sistemática para retratar a morte verifica-se, sobretudo, nos seguintes aspectos:

1. Há narrativas biográficas em que Plutarco não termina com a morte do protagonista, mas com um ou mais capítulos dedicados aos descendentes ou ao destino dos seus inimigos; as biografias de César, ${ }^{14}$ Demóstenes, ${ }^{15}$ Pelópidas, ${ }^{16}$ Demétrio $^{17}$ e António ${ }^{18}$ são alguns exemplos em que isto sucede;

2. Por vezes, associa-se a morte do herói a uma outra (Flaminino comparado a Aníbal $\left.{ }^{19}\right)$;

3. A morte do herói passa para plano secundário com a descrição da morte de uma outra figura, como sucede na biografia de António, em que Plutarco dedica dez capítulos aos últimos dias de vida de Cleópatra, quando António já tinha falecido;

4. Talvez por falta de fontes históricas, muitas vezes não se refere qual o destino dos restos mortais do herói.

Não pretendemos que estes aspectos sejam vistos como uma lacuna, uma vez que o próprio Plutarco, no prólogo do bios de Alexandre, refere que não tem a intenção de relatar toda a vida do biografado, mas, sem estar preso ao rigor cronológico e à continuidade temporal, selecciona os episódios que melhor podem delinear o êthos. É, pois, mediante uma fragmentação narrativa de episódios, em sucessivas sequências, detentores de uma certa autonomia dentro do conjunto da biografia, que Plutarco procura o efeito imitativo. Esta é uma característica relevante da biografia plutarquiana e que deve ser tida em conta quando verificarmos que a morte do herói pode merecer apenas umas breves linhas por parte do autor.

Plutarco nem sempre é tão exaustivo no relato das versões dos factos quanto a acribia histórica o exige. No caso dos capítulos que dedica à morte do biografado costuma referir diferentes versões, mas o próprio autor não pretende alongar-se muito nessas referências. Cite-se, a título de exemplo, um passo, em que depois de se fazer alusão a várias versões

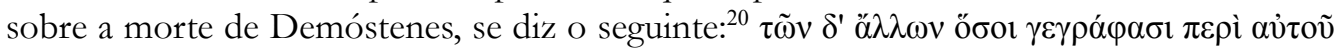

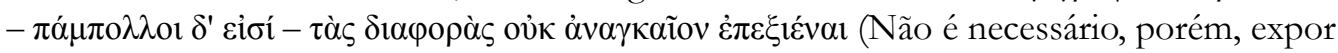

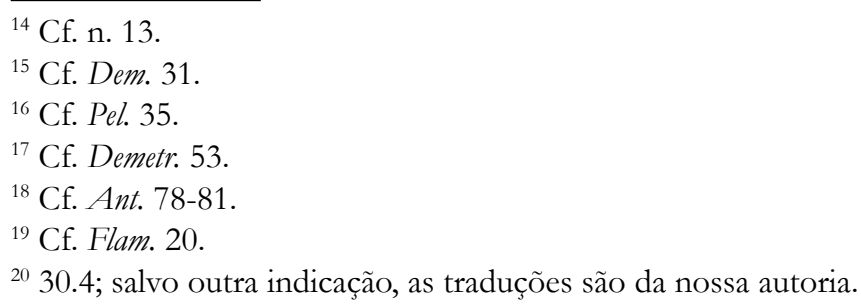


as diferentes versões ${ }^{21}$ de todos aqueles que escreveram sobre ele [Demóstenes], e que são numerosas). Apesar desta intenção, descreverá uma última versão, de Demócares, familiar

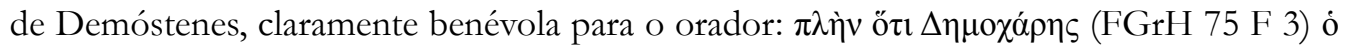

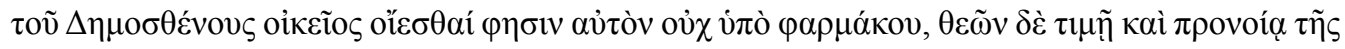

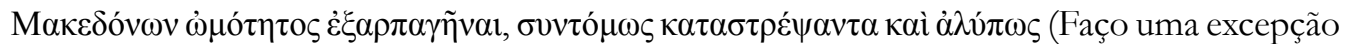
para Demócares, parente de Demóstenes, que afirma acreditar que ele não pereceu por causa de um veneno, mas que foi salvo da crueldade dos Macedónios por estima e providência dos deuses, que lhe deram um fim rápido e sem dor). Também na biografia de Alexandre, a descrição da morte, tal como ocorre na biografia de Demétrio, é simples e despida dos estereótipos da historiografia.

Veja-se o caso do par Pelópidas-Marcelo, cuja morte é anunciada pelos sinais celestes. ${ }^{22}$ Se Pelópidas, que venceu os Lacedemónios e procurou imitar Epaminondas, ${ }^{23}$ não passava de uma figura de segundo plano, Marcelo, que venceu três vezes Aníbal, foi, pelo contrário, um político de primeira linha, e ficou na história por ter vencido os Cartagineses, os Gauleses e por se ter apoderado de Siracusa. Em comum, estes heróis têm o facto de se terem deixado tomar pela temeridade e, por isso, conhecem a morte, ao porem em risco as suas vidas de forma inconsciente e irreflectida ( $\dot{\alpha} \lambda \sigma \gamma i ́ \sigma \tau \omega \varsigma^{24}$ ou $\left.\pi \alpha \rho \alpha \lambda o ́ \gamma \omega \varsigma^{25}\right)$, no posto de comando contra os inimigos espartanos e cartagineses, respectivamente. Plutarco justifica, da seguinte forma, as escolhas de Pelópidas e Marcelo como par biográfico: ${ }^{26}$

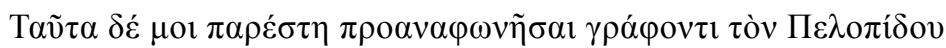

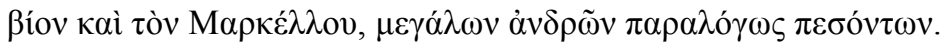

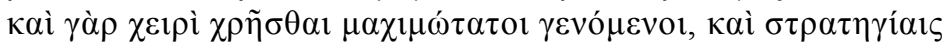

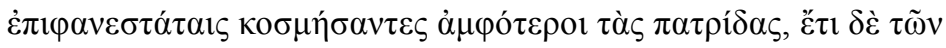

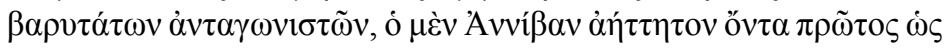

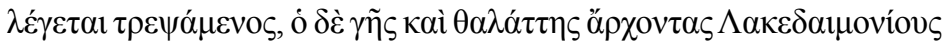

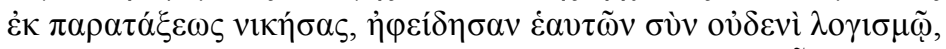

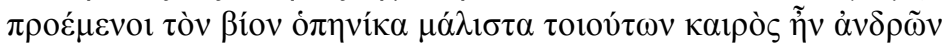

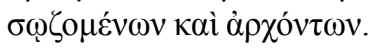

\footnotetext{
${ }^{21}$ Em Ps.-Plut., Vit. X or. 847A-B, entre as várias fontes usadas sobre a morte do orador ateniense, notámos o nome de Filócoro que em Dem. não aparece, além de fazer alusão a outras fontes anónimas segundo as quais Demóstenes morreu de falta de respiração.

${ }^{22}$ Igual prenúncio na biografia de Marcelo (cf. Marc. 29.9-11).

${ }^{23}$ Tanto Epaminondas como Pelópidas são célebres generais tebanos que se evidenciaram pela sua valentia e por serem extraordinários estrategos (cf. Reg. et imp. apopht. 192C-194E e De Alex. fort. aut uirt. 344D); entre a riqueza de Pelópidas e a pobreza de Epaminondas, institui-se a emulação da virtude (cf. Pel. 3.4-8), resultado que Plutarco visa sempre nas suas synkríseis.

${ }^{24}$ Pel. 1.1.

${ }^{25}$ Ibid. 2.9.

${ }^{26}$ Ibid. 2.9-11.
} 
Estas são as considerações que me ocorrem para introduzir a biografia de Pelópidas e a de Marcelo, homens ilustres que tombaram na guerra de forma irreflectida. De facto, os dois eram muito agressivos na forma como se entregavam à acção e honravam a sua pátria com campanhas militares. Um foi o primeiro, segundo se diz, a pôr em fuga Aníbal, que era, até ao momento, invencível, o outro venceu em campo aberto os Lacedemónios, que dominavam por terra e por mar. Os dois expuseram-se ao perigo sem reflexão, descuidando as suas vidas num momento em que se pedia a tais homens que, acima de tudo, se conservassem vivos e ao comando.

Estas palavras finais do prólogo confirmam as considerações que Plutarco vinha tecendo desde o início sobre a morte e o papel do $\sigma \tau \rho \alpha \tau \eta \gamma$ ó, defendendo que o chefe de Estado deve proteger-se dos inimigos e, como cabeça de um conjunto de homens, ${ }^{27}$ não deve expor-se em excesso para não colocar a vida dos que dependem dele em perigo. ${ }^{28} \mathrm{~A}$ propósito de colocar a vida em risco, o Queronense defende que não se deve repreender quem foge da morte por desejar viver em defesa de nobres valores, tal como não é digno de louvor aquele que enfrenta a morte com falta de prazer pela vida. ${ }^{29}$

Há, no entanto, uma característica partilhada por ambos, que figura no prólogo deste par e que acaba por ser um dos elementos centrais da sýnkrisis: a morte ou, por outras palavras, a maneira como os dois heróis se entregaram aos seus objectivos, sem pensar no valor da vida. ${ }^{30}$ Segundo a concepção plutarquiana, Pelópidas e Marcelo, embora mereçam rasgados elogios pela sua audácia e pela capacidade de liderança, têm um fim absurdo, uma vez que morrem por ambicionarem a vingança e a glória, descurando a razão. Por conseguinte, defende-se a noção de que é melhor vencer e sobreviver, pois uma morte nestas circunstâncias é mais digna de um soldado do que de um general.

Se bem que se evite na sýnkrisis atribuir a superioridade a um dos dois, no momento em que se refere à trágica morte de ambos, percebe-se que o Romano é mais distinto, ${ }^{31}$ até

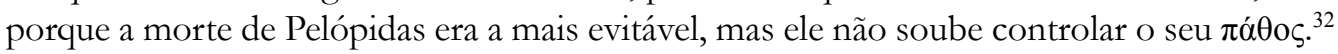
Com este facto, Plutarco assume mais uma vez o valor da paideía no controlo dos excessos, ${ }^{33}$

\footnotetext{
${ }^{27}$ Plutarco recorre à distinção e distribuição de funções feitas por Ifícrates (Cf. Pel. 2.1).

${ }^{28}$ Em Pel. 35.1, Plutarco parece querer reabilitar o final de Pelópidas.

${ }^{29}$ Ibid. 1.8.

${ }^{30}$ Cf. Comp. Pel.-Marc. 3.

${ }^{31}$ García Moreno (1996, p. 362), apoiando-se em M. Mühl (1925), considera que o retrato idealizado de Marcelo se deve ao facto de Plutarco ter usado como fonte preferencial Posidónio; esse uso explicará também que Marcelo seja a única biografia de um romano do final da República com um correspondente grego do período clássico e não da época helenística, sendo esta normalmente menos valorizada pelos intelectuais do tempo de Plutarco (cf. Bowie, 1970, p. 15ss.); sobre a escolha dos heróis, vide J. Geiger (1995, p. 174ss.).

${ }^{32}$ Cf. Comp. Pel.-Marc. 3.3.

${ }^{33}$ Cf. Cor. 1.3-5 e Mar. 2.2-4.
}

Classica, e-ISSN 2176-6436, v. 31, n. 2, p. 101-112, 2018 
neste caso com a particularidade de Marcelo, um Romano, representar melhor os princípios helénicos. Note-se, ainda, como Plutarco usa o motivo da morte e das suas circunstâncias para distinguir os heróis.

Ainda na biografia de Marcelo, Plutarco narra o episódio do encontro entre Arquimedes e Marcelo, em Siracusa, local que é um símbolo do encontro de culturas. ${ }^{34}$ Marcelo vivia uma situação pouco cómoda, por sentir, por um lado, a vontade de vencer e, por outro, pelo respeito que Arquimedes e a sabedoria grega lhe mereciam. Uma das suas maiores preocupações era tratar os vencidos de forma respeitosa e é por isso que, quando recebe a notícia da morte de Arquimedes, fica desolado: ${ }^{35}$

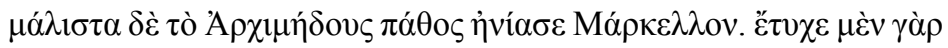

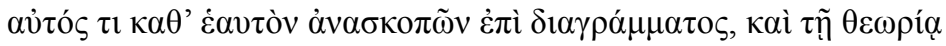

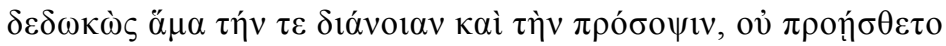

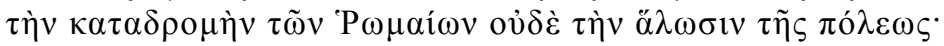

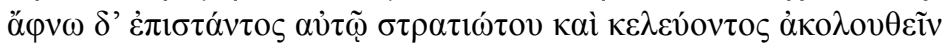

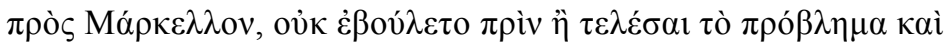

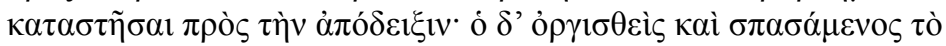

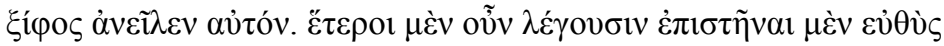

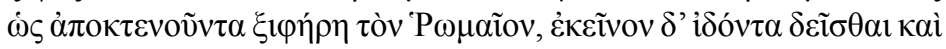

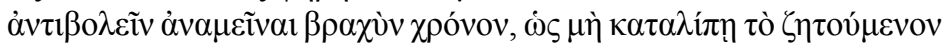
$\dot{\alpha} \tau \varepsilon \lambda \grave{\varepsilon} \zeta \kappa \alpha i ̀ ~ \dot{\alpha} \theta \varepsilon \omega ́ \rho \eta \tau o v, \tau o ̀ v \delta>$ ov̉ $\varphi \rho o v \tau i ́ \sigma \alpha v \tau \alpha \delta 1 \alpha \chi \rho \eta ́ \sigma \alpha \sigma \theta \alpha 1$.

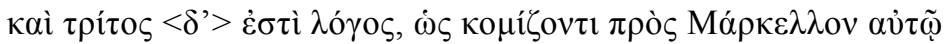

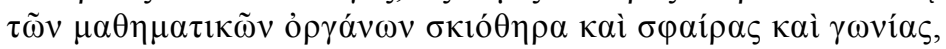

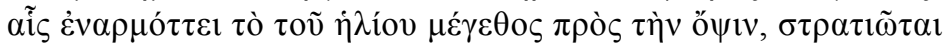

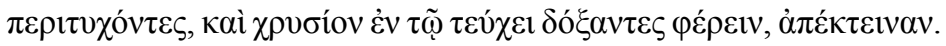

Foi a morte de Arquimedes o que mais atormentou Marcelo. Arquimedes, sozinho, encontrava-se a examinar uma figura geométrica e, concentrando a reflexão e o olhar na contemplação desta, não se apercebeu da incursão dos Romanos nem da tomada da cidade. Subitamente, aproximou-se dele um soldado que lhe deu ordem para o acompanhar até Marcelo, mas Arquimedes não quis ir, antes de resolver o problema e de ter feito a demonstração. Irritando-se, o soldado tirou a espada e matou-o. Outros dizem que um Romano armado com uma espada se aproximou dele com a intenção de o matar, mas Arquimedes, ao vê-lo, pediu-lhe e suplicoulhe para esperar um pouco, de modo a não deixar a sua pesquisa incompleta e sem ter sido demonstrada, mas o soldado, sem pensar, matou-o. Segundo uma terceira versão, Arquimedes, quando levava a Marcelo instrumentos matemáticos, como quadrantes solares, esferas e esquadros, que permitiam ver a grandeza do sol, foi encontrado,

\footnotetext{
${ }^{34}$ Cf. Marc. 20.

${ }^{35}$ Ibid.19.8-11.
} 
por mero acaso, por dois soldados, e estes, julgando que levava ouro na bolsa, mataram-no.

Os acontecimentos que envolvem a morte de Arquimedes indiciam que a justiça e o respeito pelo inimigo eram qualidades que os soldados de Marcelo não tinham interiorizado, podendo colocar-se a hipótese de que eles, por não conhecerem Arquimedes e muito menos o seu mérito científico, o mataram como matariam qualquer outro inimigo. Além disso, a descrição de Plutarco vem demonstrar, mais uma vez, a seriedade e o empenho com que Arquimedes se dedicava aos seus estudos. Se as versões, quanto à morte do matemático, não são coincidentes, já em relação ao tratamento digno e respeitoso - expresso na forma

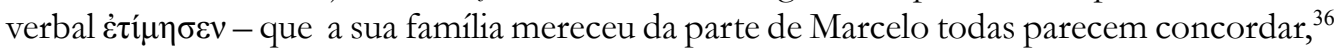
argumento que se insere no tom elogioso que Plutarco dispensa ao Romano. Realce o facto de o contexto da morte de Arquimedes servir de apoio à caracterização moral de Marcelo.

Na sýnkrisis do par Êumenes-Sertório, por sua vez, Plutarco também compara a morte dos dois heróis, tendo Sertório sido surpreendido, enquanto Êumenes já esperava o seu fim. Além disso, considera Plutarco que a morte de Sertório não foi, de modo algum, digna do valor que ele evidenciou durante a vida, ao passo que Êumenes não soube enfrentar a morte com humildade. ${ }^{37}$ Aliás, este acaba por ser mais um argumento para se defender a preferência de Plutarco por Sertório, pois constrói um retrato idealizado deste, sublimando as suas acções com a noção de que até as naturezas mais excelentes podem ser alteradas

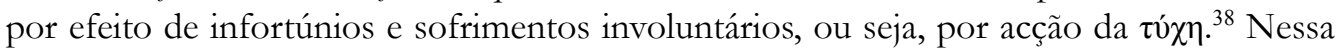
perspectiva, Sertório não é um traidor, pois a ele se deve a introdução de costumes romanos entre Iberos e Lusitanos, ${ }^{39}$ sinal de que se manteve fiel à sua romanidade. Se sobre a morte de Sertório, Plutarco pouco mais refere do que o ataque de que o Romano foi vítima por parte de António e dos conjurados, já em relação à morte de Êumenes a descrição é bastante mais pormenorizada. Não só temos a noção de que os últimos dias de Êumenes são de grande sofrimento, pois Antígono reserva-lhe uma morte lenta, privando-o de alimento. Mesmo assim, Êumenes, neste momento tão dramático, revela o seu orgulho ao afirmar que "nenhum dos homens com quem me encontrei é mais forte do que eu". ${ }^{40}$ Acabará por ser degolado e Antígono entrega os restos mortais aos amigos para serem cremados. As cinzas são recolhidas e colocadas numa urna de prata para serem entregues à mulher e aos filhos. No final da biografia de Sertório, pelo contrário, nada é dito sobre os restos mortais do herói.

\footnotetext{
${ }^{36}$ Ibid. 20.12 .

${ }^{37}$ Coragem na hora da morte em Comp. Sert.-Eum. 2.6-8; parece haver alguma contradição com aquilo que Plutarco escreveu em Eum.17-19.

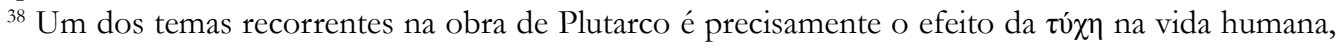
como sucede no tratado A fortuna ou a virtude de Alexandre.

${ }^{39}$ Cf. Sert. 22. Recordamos as palavras que Corneille coloca na boca do protagonista: "Rome n' est plus dans Rome, elle est toute où je suis" (Sertorius, Acto III, Cena $1^{\mathrm{a}}$ ).

${ }^{40}$ Eum. 18.
} 
Na biografia de Aristides, bem como na de Catão Censor ou de Sólon, Plutarco usa um outro efeito retórico quando estabelece uma clara relação entre o início da biografia e o seu final. Além do patriotismo, Plutarco salienta a virtude moral de Aristides, ateniense que lutou pela defesa da liberdade da Hélade. Apesar de ter desempenhado vários cargos e de ter tido sob a sua responsabilidade um assunto tão importante como a constituição económica da Liga de Delos, o que certamente agitaria vários interesses, Aristides provou que entendia a $\pi$ o $\lambda \imath \tau \varepsilon i ́ \alpha$ como um serviço em prol do bem público. A prova de que não tirou qualquer proveito pessoal da sua acção política foi, como Plutarco enfatiza, o facto de ter abandonado o cargo mais pobre do que quando o assumiu, tendo inclusive feito um

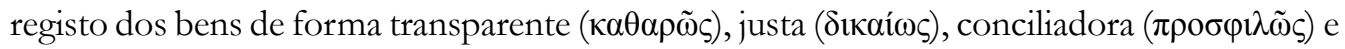

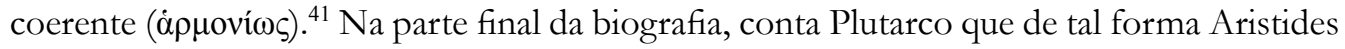
não tirou qualquer proveito da sua actividade na Liga de Delos que a sua descendência viveu na miséria. Depois da sua morte, nem ele próprio mereceu um túmulo digno dos seus feitos em prol da Hélade, nem a sua família ou as suas filhas, que casaram graças a um dote suportado por fundos públicos, herdaram bens que lhes evitassem a pobreza: ${ }^{42}$

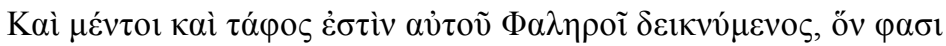

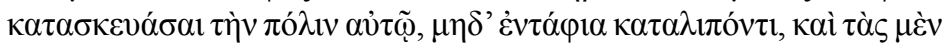

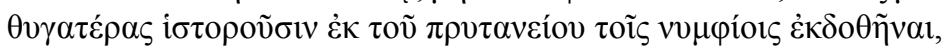

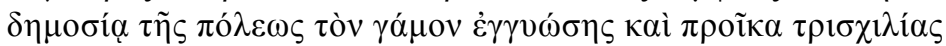

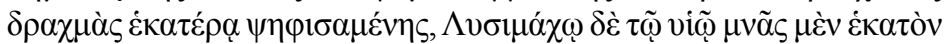

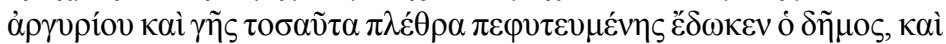

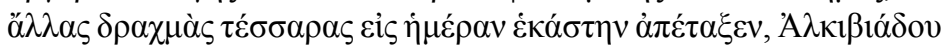
$\tau$

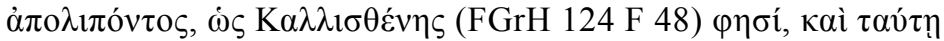

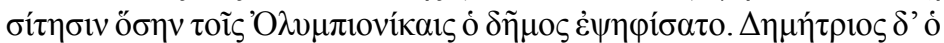

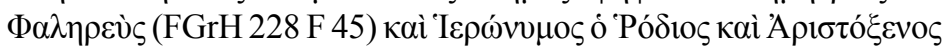

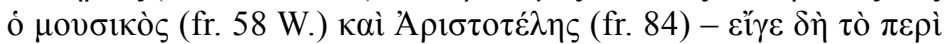

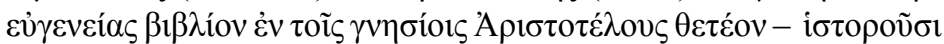

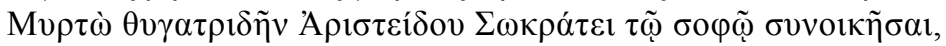

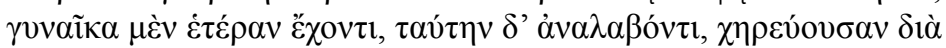

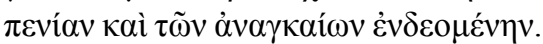

E note-se que o sepulcro dele está exposto em Falero e que, segundo dizem, foi a cidade que o preparou para ele, pois Aristides nada deixou para a cerimónia fúnebre; contam que as filhas dele casaram com jovens noivos graças ao pritaneu, pois a cidade financiou com bens públicos o casamento, ao decretar que se dessem três mil dracmas, a título gratuito, para cada uma delas. Ao filho Lisímaco o povo deu cem minas de prata e igual número de pletros em terra cultivada, e consignou-lhe outras quatro dracmas ao dia, por decreto

\footnotetext{
${ }^{41}$ Ibid. 24.2.

${ }^{42}$ Ibid. 27.1-3.
} 
de Alcibíades. Depois, Lisímaco ao morrer deixou uma filha de nome Polícrite, para a qual, como refere Calístenes, o povo decretou um alimento igual ao dos vencedores olímpicos. Demétrio de Falero, Jerónimo de Rodes, o músico Aristóxeno e Aristóteles — se é que se pode considerar o pequeno livro Sobre a nobreza como uma obra autêntica de Aristóteles - contam que Mirto, neta de Aristides, viveu com o sábio Sócrates, que já tinha uma mulher, mas acolheu-a, por ela estar desamparada pela sua pobreza e carecer dos bens essenciais.

Note-se que todos estes episódios relacionados com a sepultura de Aristides e o apoio da pólis à sua família reforçam a primazia que durante a vida deu à moralidade e à ética no exercício de funções públicas, não deixando fortunas como herança aos seus descendentes, mas a sua reputação de homem justo, indulgente e patriótico.

Catão Censor, por sua vez, é descrito por Plutarco como um homem que mostrou toda a sua firmeza e objectividade pela maneira como soube reagir à vitória e ao êxito, ${ }^{43}$ uma vez que, contrariamente à maioria, não se entregou às ociosidades ( $\sigma \chi 0 \lambda \alpha i)$ e ao prazer

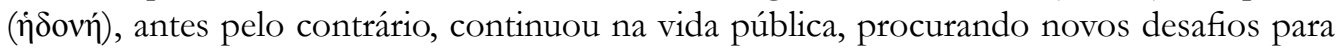

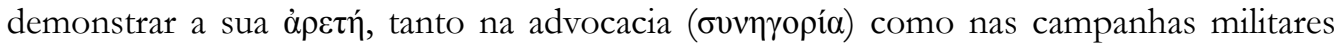
$(\sigma \tau \rho \alpha \tau \varepsilon i ́ \alpha \iota) \cdot{ }^{44}$ Rigoroso no exercício da politeía, Catão manteve-se activo até ao final da sua vida $a^{45}$ - princípio que Plutarco aprecia e defende nos tratados políticos - sabendo, por

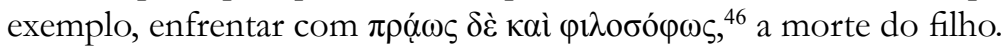

De forma diferente, é tratado o tema da morte do herói no par Filopémen-Flaminino, sobretudo porque na biografia do Romano assume particular protagonismo a morte de Aníbal, estabelecendo-se um paralelo entre essa morte e a de Filopémen. Embora enfatize a

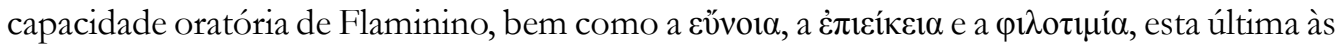
vezes de forma desmesurada, Plutarco não esconde que o herói romano se deixou dominar, com frequência, pela irracionalidade do $\theta v \mu$ ós, embora tenha conseguido atenuar o seu efeito nas acções. A parte final da biografia parece, porém, indicar o contrário. ${ }^{47} \mathrm{Com}$ os seus cerca

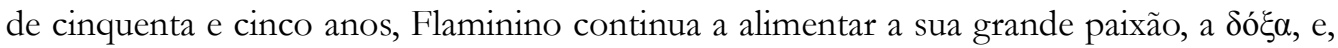
por isso, indigna-se com o facto de Aníbal continuar vivo. Revelando a sua natural ambição, Flaminino contribuiu para apressar o fim de Aníbal, o qual mostrou ser um homem hábil e experiente ${ }^{48}$ Essa motivação foi entendida como um sinal da crueldade de Flaminino, por

\footnotetext{
${ }^{43}$ cf. Cat. Ma. 19.6: reprova o louvor por estátuas (cf. Praec. ger. reip. $820 \mathrm{~B}$ e E).

${ }^{44}$ Ibid. 11.4.

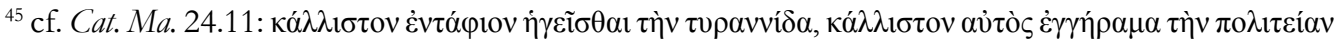

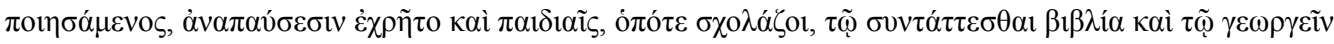
(Ele tornou a política a mais bela actividade da sua velhice, e quando estava num momento de ócio, entrega-se a escrever livros e a trabalhar na agricultura, para descansar e se entreter); cf. Alex.40.2, quase igual a Dem. 22.3 (álopos e prâos).

${ }^{46}$ Cat. Ma. 24.10.

${ }^{47}$ Cf. ibid. 20.

${ }^{48}$ Cf. ibid. 21.8.
}

Classica, e-ISSN 2176-6436, v. 31, n. 2, p. 101-112, 2018 
querer juntar o seu nome à morte de Aníbal, de forma a alcançar a glória. ${ }^{49}$ Assim, o epílogo desta biografia, ao contrário daquilo que se poderia esperar, não acentua as diferenças da

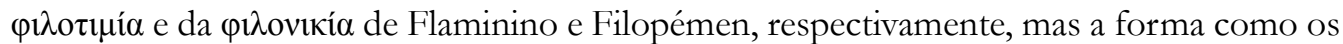
últimos dias destes heróis são semelhantes. ${ }^{50}$ Quanto a Filopémen, no final da sua vida, ${ }^{51}$ muito embora ainda mantivesse alguma agilidade, ambicionava mais a paz do que a guerra, ${ }^{52}$

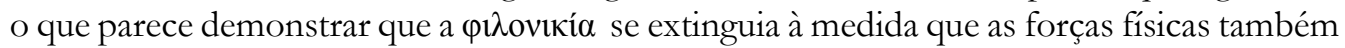
diminuíam. Este homem, que ficaria conhecido pela luta audaz e brilhante ${ }^{53}$ que travou por amor à Grécia e à liberdade, entregar-se-ia de forma voluntária à morte, acontecimento que provocou grande tristeza entre o povo.

Juntamos um último exemplo, o da biografia de Mário. Marcado por várias desventuras, após uma vida bastante intensa, Mário seria atingido por uma pleurisia, ${ }^{54}$ segundo Posidónio. No entanto, de acordo com uma outra fonte, o historiador Gaio Pisão, Mário, após um jantar com amigos, recolheu-se aos seus aposentos, onde acabaria por morrer passados sete dias. Parece que durante esse tempo viveu atormentado por delírios, em que imaginava ser general na guerra contra Mitridates. Conclui Plutarco que Mário, apesar de ter vivido setenta anos, de ter sido cônsul sete vezes e da riqueza que o rodeou, lamentava-se da sua $\tau u ́ \chi \eta$, por pensar que morria com falta de bens e sem ter cumprido os seus desejos. A esta atitude de Mário no fim da vida, contrapõe Plutarco a figura de Platão que deu graças ao

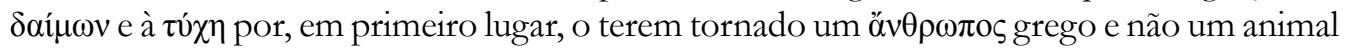
irracional, evitando a barbárie, e, em segundo lugar, por ter vivido no tempo de Sócrates.

Poderíamos, certamente, acrescentar mais exemplos de descrição da finitude dos heróis de Plutarco. Parece-nos, ainda assim, que a nossa exposição prova como os capítulos finais das biografias de Plutarco não se regem por uma metodologia rígida, mas antes diversa na sua forma e até no conteúdo. A principal razão para isso suceder poderá ser o facto de a morte do herói ser mais um acontecimento que deve contribuir para a construção do seu retrato ético e psicológico. Se o objectivo é mostrar que até ao fim da sua vida o herói manteve o mesmo carácter elevado, mais do que ser exaustivo na descrição das diversas versões sobre as circunstâncias da morte, importa ao biógrafo indicar, de forma por vezes bastante sucinta e depurada de efeitos retóricos, o término do herói. Além disso, o sentido moral e pedagógico das Vidas visa transmitir que o homem, para não estar dependente das incertezas da sorte, deverá dedicar-se à paideía, pois será ela o melhor baluarte para enfrentar as contingências próprias da condição humana, como é o caso da morte. Pelos exemplos expostos podemos também concluir que Plutarco usa, várias vezes, a descrição da morte para complementar a caracterização do herói biografado.

\footnotetext{
${ }^{49}$ Em ibid. 21.6, Plutarco refere que a maioria considera Cipião superior a Flaminino pela forma como lidou com Aníbal.

${ }^{50}$ Para uma análise desta sýnkrisis, vide T. Duff (2002r, p. 267ss.).

${ }^{51}$ Pelling (1989, p. 212-3) estabelece um paralelo entre a morte de Filopémen (Phil. 21.1-2) e a de Aníbal (Flam. 21.1-6), pois ambos são vítimas da falta de magnanimidade dos adversários.

${ }^{52}$ Cf. Phil. 18.1.

${ }^{53}$ Cf. Phil. 12.4-6; Praec. ger. reip. 817E.

${ }^{54}$ Cf. Mar. 45.7.
} 


\section{REFERÊNCIAS}

BOWIE, E. The Greeks and their Past in the Second Sophistic. Past \& Present, v. 46, p. 3-41, 1970.

DUFF, T. Plutarch's Lives. Exploring Virtue and Vice. Oxford: Oxford University Press, 2002r.

EAGLETON, T. First-Class Fellow Traveller [Review of Sean French's Patrick Hamilton: a Life. London Review of Books, v. 15, n. 23, p. 12, 1993.

GARCÍA MORENO, L. Plutarco y la Rapacidad de los Romanos. In: FERNÁNDEZ DELGADO, J.; PORDOMINGO PARDO, F. (Eds.). Estudios sobre Plutarco: Aspectos Formales, Actas del IV Simposio Español sobre Plutarco (Salamanca, 26 a 28 de Mayo de 1994). Madrid: Ediciones Clásicas, 1996. p. 357-67.

GEIGER, J. Plutarch's Parallel Lives: The choice of heroes. In: SCARDIGLI, B (Ed.). Essays on Plutarch's Lives. Oxford: Oxford University Press, 1995. p. 165-90. (= Hermes 99 (1981: 85-104)).

GRIBBLE, D. Alcibiades and Athens: A Study in Literary Presentation. Oxford: Clarendon Press, 1999.

MÜHL, M. Poseidonios und der Plutarchische Marcellus, Klassisch-Philologische Studien 4, Berlin: Verlag von Emil Ebering, 1925.

PELLING, C. Plutarch: Roman heroes and Greek culture. In: GRIFFIN, M.; BARNES, J. (Eds.). Philosophia Togata. Essays on Philosophy and Roman Society. Oxford: Clarendon Press, 1989. p. 199-232.

PELLING, C. 'You for me and me for you...': narrator and narrative in Plutarch's Lives. In Plutarch and History. The Classical Press of Wales and Duckworth, 2002a. p. 267-82.

PELLING, C. Is death the end? Closure in Plutarch's Lives. In: Plutarch and History. The Classical Press of Wales and Duckworth, 2002b. p. 365-86.

PÉREZ JIMÉNEZ, A. Introducción General. In: Plutarco. Vidas Paralelas I (Teseo-Rómulo, Licurgo-Numa). Madrid: Gredos, 2000r.

PINHEIRO, J. A escrita biográfica de Plutarco. In: MORÃO, P.; INFANTE DO CARMO, C. (Orgs.). ACT 16 - Escrever a vida: Verdade e fição. Porto: Campo das Letras, 2008. p. 317-37.

PINHEIRO, J. Tempo e espaço da paideia nas Vidas de Plutarco. Coimbra: Imprensa da Universidade de Coimbra, Classica Digitalia, 2013.

ROSENMEYER, T. Beginnings in Plutarch's Lives. Yale Classical Studies, v. 29, p. 205-30, 1992. STADTER, P. The Proems of Plutarch's Lives. Illinois Classical Studies, v. 13, n. 2, p. 275-95, 1988. 